\title{
Ask for What You Need, Not What You Want
}

\author{
Douglas Sellinger
}

A ccording to one presenter at the 2011 Governance Summit of the Canadian Society of Association Executives (held in Calgary in November 2011), advocacy can be defined as effective clout influencing other people's beliefs and behaviours that affect the things that are significant to the advocate. As an example, most of us can relate to a 2-year-old "advocating" for a new toy. The child doesn't merely want the toy; he truly needs it. He quickly gets his message across with focused cries, begging, and possibly a tantrum. Many times, this simple form of advocacy is effective in achieving the desired result, a new toy.

The CSHP Vision 2014 includes "Advocating for the profession". Since joining the Society's Executive during the 2011 Summer Educational Sessions, I have become immersed in advocacy issues, and I can comfortably report that we continue to follow this aspect of our Vision. Notably, members of the Advocacy Committee were busy last fall not only creating and launching the current advocacy mailing campaign but also educating themselves on how to be effective advocates to enhance the success of future advocacy activities.

When Sister Elizabeth Davis, former Chief Executive Officer (CEO) of the Health Care Corporation of St John's, recently spoke in my health region, she asked us to reflect on what we do to ensure that our clients are treated with dignity and respect, as well as ensuring that they are owner-partners in their care plans. She implored us to use our clout to achieve our clients' desired outcomes. This form of advocacy aligns pharmaceutical care plans with the achievement of clients' desired outcomes. I believe this is a prime reason why most of us became pharmacists and chose to work in hospitals and related health care settings. The challenges are to understand what our clients need and to align those needs with what they want.

A similar principle may come into play when we advocate as an organization. Often, we think that if the health minister or

a hospital's CEO only understood things the way we do, he or she would want to help us succeed. In other words, we want to advocate through education. However, what we may be missing is an understanding of the minister's or CEO's needs. What the Advocacy Committee has learned is that

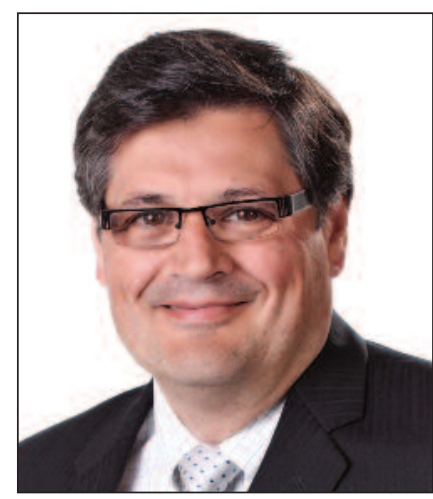
many key decision-makers require a single question or "ask". The "ask" should express exactly what we need, like the 2-yearold who needs a toy. The "ask" should require a specific action to be taken and should benefit both the decision-maker and the requester. When decision-makers see that working with us is to their benefit as well as ours, both parties are more likely to get what they want.

National and branch volunteers and staff within CSHP are advocating on your behalf-we want to make CSHP the advocate for hospital pharmacists, and we need your trust, assistance, and ideas to ensure that CSHP continues to be the national voice of pharmacists committed to patient care through the advancement of safe, effective medication use in hospitals and other collaborative health care settings. My "ask" to all of you is for your continued support of CSHP advocacy for hospital pharmacists. You show this support through your membership and by volunteering with CSHP at the chapter, branch, and national levels. For this, I thank you, and I am proud to advocate with you.

Douglas Sellinger, BSP, MALT, is the President Elect and External Liaison for the Canadian Society of Hospital Pharmacists. 